\title{
Repensar a Criação no mundo da Tecnociência e do Mercado
}

\author{
Rethinking Creation in the world \\ of Technoscience and the Market
}

Sinivaldo Silva Tavares

\section{Resumo}

O Mercado e a Tecnociência constituem horizontes de fundo no interior dos quais se desvelam todos os âmbitos da experiência humana. A Tecnociência tornou-se horizonte de compreensão do ser humano em relação ao mundo e si próprio. Não apenas nossos estilos de vida, nosso modo de trabalhar e viver, são condicionados pela técnica, mas também nossa identidade mais profunda é dada pela diferença técnica. Somos também vítimas de um fenômeno descrito como "absolutização do Mercado", caracterizado pela mercantilização da vida. O mercado vai se impondo como único cenário de nossa trama civilizacional atual. Nossos fluxos vitais e também os valores e símbolos culturais e religiosos se tornam mercadoria de consumo e de descarte. Portanto, como elaborar um discurso acerca da Criação que, acolhendo com responsabilidade os desafios provenientes desse preciso contexto, se proponha como genuinamente cristão e ainda relevante neste início de século XXI?

Palavras-chave: Mercado. Tecnociência. Ecologia. Criação.

\section{Abstract}

The Market and Technoscience represent a deep horizon, within which the ambit of human experience is unveiled. Technoscience has become the human horizon of understanding with respect to the world and the individual 
person. Not only are our lifestyles and ways of working and living conditioned by technology but, also, at a deeper level, our identity is defined by this technological difference. We, too, are victims of a phenomenon described as "Market Absolutism", characterized by the commodification of life. The Market continues to imose itself as the only scene in the plot of our present civilization. Our vital streams, values, and cultural and religious symbols become commodities of consumption and disposal. Therefore, how do we elaborate a discourse around Creation, responsibly drawing in the prevailing challenges of this context, that can be understood as genuinely Christian and still relevant at the beginning of the twenty-first century.

Keywords: Market. Technoscience. Ecology. Creation.

\section{Introdução}

Vivemos, hoje, sob a hegemonia do paradigma da Tecnociência e do Mercado. Ambos, Mercado e Tecnociência, constituem autênticos horizontes no interior dos quais se desvelam todos os âmbitos da experiência humana. A Tecnociência tornou-se horizonte de compreensão do ser humano em relação ao mundo e a si próprio. Não apenas nossos estilos de vida, nosso modo de trabalhar e viver, são condicionados pela técnica, mas também nossa identidade mais profunda é dada pela diferença técnica. Somos ainda vítimas da "absolutização do Mercado": uma autêntica mercantilização da vida. O mercado vai se impondo como único cenário de nossa trama civilizacional atual. Nossos fluxos vitais e também os valores e símbolos culturais e religiosos se tornam mercadoria de consumo e de descarte. Portanto, como falar acerca da Criação nessa nova situação epocal?

\section{O paradigma hegemônico: uma engrenagem entre Mercado e Tecnociência}

1.1. Da economia de Mercado à sociedade de Mercado: uma grande transformação

Constatamos um processo em curso descrito como "absolutização do Mercado". Trata-se daquela "grande transformação" descrita por Karl Polanyi como passagem da "economia de mercado" para a "sociedade de 
mercado". O Mercado vai se impondo sempre mais como único cenário de nossa trama civilizacional atual. Esta nova configuração produz um fenômeno correlato: a "mercantilização da vida". Em que consistiria propriamente esse processo? Nossos fluxos vitais são reduzidos impiedosamente a simples mercadorias de consumo e de descarte. Analistas agudos tem se debruçado sobre esse fenômeno que tem acometido nossas sociedades contemporâneas²

A origem de tal fenômeno talvez deva ser buscada no bojo do Capitalismo ocidental em sua fase recente. Para caracterizá-la empregam-se os adjetivos: imaterial, simbólico e cognitivo. A imaterialidade remeteria à transformação da cultura material ocorrida no interior do próprio sistema capitalista. Exige-se, atualmente, cada vez menos trabalho para a confecção material dos produtos, fazendo com que o custo se fragilize e, portanto, o preço das mercadorias caia. Para conter essa baixa de preços, as empresas transformam seus produtos materiais em bens imateriais, afetivos, estéticos, simbólicos.

Capitalismo simbólico porque o que conta agora não é tanto a utilidade prática do produto quanto o simbolismo do qual ele foi revestido pelo Mercado e pela Mídia. O que importa, no capitalismo atual, é investir no desejo subjetivo do consumidor de alcançar, mediante o consumo de determinados produtos, prestígio, personalidade, autoafirmação identitária. E, por fim, Capitalismo cognitivo porque o valor da mercadoria não é estabelecido apenas em função da força de trabalho e do tempo investidos na transformação da matéria prima em produto. Nessa nova fase, os preços referem-se, sobretudo, ao acúmulo de conhecimento embutido no produto final a ser consumido.

Portanto, mediante a queda do valor real dos produtos materiais e o aumento artificial do valor de troca do imaterial, do simbólico e do cognitivo, verifica-se, em última análise, o desmoronamento dos fundamentos da clássica economia política: conhecimento, trabalho material e capital ${ }^{3}$. Ingressamos assim em nova fase do Capitalismo ocidental. Não mais capitalismo de produção, mas, agora, capitalismo de consumo. Em tal contexto, compreende-

${ }^{1}$ Cf. POLANYI, K. A grande transformação. As origens da nossa época. Rio de Janeiro: Campos, 2000.

${ }^{2}$ Cf. LIPOVETSKY, G. O império do efêmero. A moda e seu destino nas sociedades modernas. São Paulo: Companhia das Letras, 2006; BAUMAN, Z. Vida para consumo. A transformação das pessoas em mercadoria. Rio de Janeiro: Zahar, 2008; ASSMANN, H.; HINKELAMMERT, F. A idolatria do Mercado. Ensaio sobre economia e teologia. São Paulo: Paulinas, 1989; MO SUNG, J. Idolatria do capital e a morte dos pobres. São Paulo: Paulinas, 1989.

${ }^{3}$ Cf. GORZ, A. "A crise e o êxodo da sociedade salarial”. Cadernos IHU Idéias 31. São Leopoldo: Ed. Unisinos, 2005; GORZ, A. O imaterial. São Paulo: Annablume, 2005. 
se a busca frenética por mercantilizar tudo, mediante o exacerbado inflacionamento das mercadorias visando ao consumo cada vez maior. Se antes, na era industrial, exigiam-se, na forte expressão de Michel Foucault, "corpos dóceis, disponíveis e úteis", hoje interessam "almas capacitadas", subjetividades munidas das qualidades mais cotadas e apreciadas no mercado de trabalho. Em sua nova fase, portanto, interessa ao capitalismo a produção de subjetividades consumidoras. E para incrementar o consumo e o apetite dos sujeitos consumidores é imprescindível que se invista no "fetichismo da mercadoria".

Tais processos têm se verificado sob o pressuposto da crescente supremacia do Mercado na administração dos fluxos vitais. Em nossos dias, tem se concebido e definido a vida como produto, uma simples mercadoria. Numa palavra, a vida tem se tornado mera invenção humana. E isso graças à inaudita capacidade do capitalismo do século XXI de operar um autêntico seqüestro simbólico das forças vitais. Ele não apenas captura tais forças como também consegue reciclar as resistências a esse seqüestro mediante a produção de slogans publicitários e mercadorias a serem consumidas. Até mesmo nossas bandeiras alternativas têm se tornado objeto de publicidade e, conseqüentemente, reduzidas a mercadorias sedutoras.

Com base em tais análises, o capitalismo neoliberal estaria ultimando sua hegemonia global. Na medida em que vem conseguindo transformar a vida e, portanto, também os valores e símbolos culturais e religiosos, em mercadoria de consumo e de descarte, o capitalismo neoliberal tem consolidado sua hegemonia sobre nossa inteira civilização. Falávamos acima de um processo de fetichização das mercadorias. A Mídia se tornou, em nossos dias, um mundo do qual não se pode mais prescindir. E a combinação entre Mercado e Mídia tem se revelado profundamente eficiente; os interesses escusos do Mercado são veiculados na Mídia em seu caráter profundamente sedutor. Excelentes estudos têm mostrado uma forte cumplicidade entre Mídia e Mercado na criação e manutenção dos processos descritos acima, tais como: "absolutização do Mercado", "mercantilização da vida", "fetichização da mercadoria" 4 .

\footnotetext{
${ }^{4}$ A esse propósito, remetemos a MOREIRA, A. (Org.). O capitalismo como religião. Goiânia: Ed. da PUC Goiás, 2012; MOREIRA, A.; LEMOS, C.T.; QUADROS, E.G. (Orgs.). A religião da mídia e a mídia da religião. Goiânia: Ed. da PUC Goiás - Gráfica e Editora América, 2012; ASSMANN, H.; HINKELAMMERT, F. A idolatria do Mercado. Ensaio sobre economia e teologia. São Paulo: Paulinas, 1989; MO SUNG, J. Idolatria do capital e a morte dos pobres.
} 
1.2. Do uso da técnica à emergência da Tecnociência: outra grande transformação

No interior do paradigma moderno, marcadamente antropocêntrico, atestava-se uma correlação entre "vontade de poder" do ser humano, concebido como sujeito, e "desencantamento do mundo", considerado como mero objeto à mercê do sujeito. As coisas eram vistas pelo ser humano apenas na sua utilidade. Preso, portanto, ao próprio interesse e à imagem de si, o ser humano em seu afã de controle se limitava a manter relações meramente funcionais e utilitárias. Nesse sentido, ele se auto-afirmava contra as coisas, consideradas estranhas a si, isto é, objetos a serem submetidos ou eliminados.

Em tal contexto, a técnica era utilizada pelo ser humano como instrumento privilegiado na consolidação de seu saber como poder. Com razão, se dizia que a técnica nada mais era que ciência aplicada. De fato, a técnica se prestava, na condição de instrumento, a esse domínio do sujeito pensante sobre os demais seres considerados meros objetos mensuráveis. Concebida como mero instrumento, a técnica era vista como emanação do sujeito, vale dizer, extensão de seus membros visando a potencialização de seu domínio sobre as coisas. Numa palavra, a técnica era considerada mero instrumento à disposição do ser humano no seu controle dos objetos que encontrava diante de si.

Desde algumas décadas, estamos assistindo a uma expansão vertiginosa das novas tecnologias a ponto de caracterizar uma autêntica virada epocal: da idade da técnica para a era da Tecnociência. Seria mesmo legítimo postular uma mudança de época? De mero instrumento de dominação à disposição do ser humano, como era a técnica, percebemos que a Tecnociência tornouse horizonte último no interior do qual se desvelam todos os âmbitos da experiência, chegando a condicionar inclusive a maneira de o próprio ser humano se autoconceber. Fala-se, a tal propósito, da co-presença de dois processos simultâneos: a "emergência da tecnosfera" e o "deslocamento da subjetividade".

Concebe-se o termo "tecnosfera" como uma espécie de horizonte no interior do qual se produzem novas mentalidades e visões de mundo. Superase, por exemplo, aquela visão mecanicista e geométrica da física clássica e sua função domesticadora. Agora, na era da Tecnociência, a natureza é

São Paulo: Paulinas, 1989. 
decomposta e, afinal, recriada segundo os moldes da ciência informática e da biologia molecular. Em outras palavras, as novas tecnologias não são mais meros instrumentos a serviço do ser humano na perseguição de determinados fins. Elas se tornaram, para todos os efeitos, produtoras de necessidades das quais o ser humano se torna cada vez mais dependente.

Fala-se em "deslocamento da subjetividade" pelo fato de que o ser humano, nas contundentes palavras do filósofo italiano, Umberto Galimberti, "não é mais sujeito, mas algo disposto no horizonte desvelado pela Tecnociência, que é, afinal, o que decide o modo de ele se perceber, sentir, pensar e projetar"'. O ser humano não é mais capaz de se perceber fora do mundo disposto pela Tecnociência, uma vez que ela se tornou o ambiente no qual o ser humano chega ao conhecimento de si. Por essa razão, justifica-se o uso do termo "Tecnociência" em vez de "técnica" simplesmente ou do adjetivo "científico-técnico". A Tecnociência tornouse o horizonte de fundo dentro do qual a própria ciência encontra ou não sua legitimidade ${ }^{6}$.

A constatação da simultaneidade dos processos de "emergência da tecnosfera" e de "deslocamento da subjetividade" justificaria por si só a necessidade de uma hermenêutica própria para se compreender o fenômeno da Tecnociência. Não se poderia, a rigor, continuar falando de um mundo à medida do ser humano; dever-se-ia, pelo contrário, falar agora de um ser humano à medida do mundo. A relação entre Tecnociência e ser humano se torna mais complexa ainda quando se têm presentes os recentes processos de hibridização entre ambos. As novas tecnologias não se contrapõem ao ser humano. Em sua autonomia, elas se tornam capazes de integrar o ser humano em seu aparato técnico. E, a partir daí, cria-se o sistema homem-máquina no interior do qual os comportamentos humanos se reduzem a partes de máquinas que, por sua vez, passam a ser reguladas pelas tecnologias. Com razão, escreve R. Marchesini:

A tecnologia transforma a epistêmica humana, importa modelos não-humanos na dimensão, modifica a percepção formativa que o homem tem de si mesmo, facilita os processos de trocas referenciais

\footnotetext{
${ }^{5}$ GALIMBERTI, U. Psiche e techne. O homem na idade da técnica. São Paulo: Paulus, 2006, p. 383.

${ }^{6}$ Cf. GALIMBERTI, U. Psiche e techne. O homem na idade da técnica. São Paulo: Paulus, 2006, pp. 391-393.
} 
com o não-humano; enfim conjuga e hibridiza, não separa nem purifica, antropodescentraliza e não reforça o pensamento antropocentrado ${ }^{7}$.

Em tal caso, a tecnologia se torna parceira do ser humano uma vez que ela modifica não apenas seu perfil, mas também sua própria constituição biológica. O que nos faz pensar que, no final das contas, toda tecnologia seria de fato uma biotecnologia. Nesse sentido, a tecnologia abre-nos para o mundo na exata proporção em que facilita os processos híbridos entre humanos e não-humanos. De fato, a tecnologia penetra no interior do ser humano a ponto de se tornar, para todos os efeitos, sua carne. E assim, o corpo humano se transforma num verdadeiro campo de aplicação das novas tecnologias e essa hibridização tem se dado numa aceleração crescente com profundas modificações no tocante aos predicados e atributos humanos.

Considerando, enfim, que a Tecnociência, em nossos dias, se tornou horizonte imprescindível de compreensão do ser humano em relação ao mundo e a si próprio, então talvez fosse o caso de nos perguntarmos: o que o ser humano se torna nessa situação epocal desvelada pelas novas tecnologias? Portanto, não apenas nossos estilos de vida, nosso modo de trabalhar e viver, são condicionados pelas tecnologias, mas também nossa identidade mais profunda é condicionada pela diferença tecnológica. E, nesta radical reviravolta, somos postos diante de uma questão dificilmente contornável não mais o que nós poderemos fazer com a tecnologia, mas o que as tecnologias podem fazer de nós.

1.3. As conseqüências de um mundo sob o controle do Mercado e da Tecnociência

Uma vez elencadas grosso modo as principais características do paradigma hegemônico, gostaríamos de fazer algumas considerações, ainda que sumárias, sobre as conseqüências do que significa viver em um mundo controlado pela Tecnociência e pelo Mercado. Algumas delas nos pareceram óbvias, e emergem quase que espontaneamente no decurso de nossa descrição do paradigma hegemônico. No entanto, talvez tenha chegado o momento de

MARCHESINI, R. "Uma hermenêutica para a tecnociência". In: NEUTZLING, I.; ANDRADE, P. F. C. de (Orgs.). Uma sociedade pós-humana. Possibilidades e limites das nanotecnologias. São Leopoldo: Editora Unisinos, 2009, pp. 155-156. 
explicitar algumas conseqüências justamente para que fique mais claro ainda a urgência de se propor uma nova teologia da criação.

Essa engrenagem pela inter-relação entre Tecnociência e Mercado produz, na verdade, uma espécie de "tecnificação" da vida. Os fluxos vitais e as relações passam a ser controladas pelo critério da funcionalidade e da aplicabilidade. Apenas o que "serve para" e o que se torna "útil a" se justificam e conquistam direito de cidadania em nossos dias. Estão, assim, postas as condições para que se instaure outro fenômeno decorrente do anterior: a "mercantilização" da vida. Se tudo quanto existe só vale enquanto é útil, então, tudo já se transformou em mercadoria disponível, à mercê das necessidades de utilidade e de consumo dos consumidores. O desfecho de uma tal situação é a redução de toda e qualquer relação segundo os padrões da mercadoria e do consumo.

A "tecnificação" da vida produz ainda uma situação em que os meios são inflacionados e até absolutizados em detrimento dos fins. Trata-se de uma total instrumentalização das relações com o conseqüente desencanto face aos valores e à ética. Vivemos assim num mundo da "impotência" da ética e do "crepúsculo" dos valores e da própria história. E, por fim, assistimos a uma sutil inversão, embora com conseqüências enormes e profundas: a substituição da eficácia pela eficiência. Nesse caso, a eficiência se torna critério decisivo de valor, de sentido e de verdade.

A própria concepção de verdade se encontra, no "mundo da tecnologia", condicionada pela noção de eficiência. A verdade da técnica é, para todos os efeitos, funcional. Não mais interessa a busca do conhecimento pelo conhecimento, mas sim do conhecimento aplicável. Trata-se da redução do logos à sua dimensão tecno-lógica (téchne + logos). Testemunha-se, portanto, a hegemonia da razão instrumental que, por sua vez, produz um processo duplo e simultâneo de desumanização da pessoa e de desnaturalização da natureza. Em seu exercício, opera-se a tradução dos fins em resultados, a redução do mistérico a incógnita matemática e, enfim, a submissão da novidade à ordem da previsão.

\section{Repensar a Criação: desafios e perspectivas}

Como elaborar um discurso acerca da Criação que, acolhendo com responsabilidade os desafios provenientes da situação descrita acima, se proponha como genuinamente cristão e, por conseguinte, relevante neste início 
de século XXI?? . Essa nova "teologia da criação" será fruto, em primeiro lugar, da releitura dos relatos bíblicos da criação ${ }^{9}$. E o intuito desta releitura será resgatar a singularidade do ser humano não operando uma separação sua das demais criaturas, mas, ao contrário, potencializando as inter e retro-relações que o ligam intensa e intimamente a essa imensa e complexa "teia da vida" (F. Capra). Ademais, essa nova "teologia da criação" ensaiará concepções igualmente novas de Deus, do ser humano e das outras criaturas a partir de uma radical inversão dos processos de redenção e criação ${ }^{10}$. Salientará, por conseguinte, a necessidade de se superar toda sorte de dualismo extrinsecista como caminho para se compreender a inteira realidade como uma complexa teia. Qual teia de relações, as distintas singularidades aparecerão melhor na medida em que explicitarmos as íntimas interconexões que as mantêm unidas nessa complexidade do real.

\subsection{Desafios: olhares viciados - relações desvirtuadas}

Constatamos que as próprias teologias engoliram a isca que lhes foi lançada pela cultura moderna. Razão pela qual, o Criador passou a ser concebido como o princípio, a origem de todas as coisas. Só que, à diferença dos relatos bíblicos, esse princípio passou a ser concebido não mais na sua

\footnotetext{
${ }^{8}$ É o que intentamos fazer de forma mais detalhada em: TAVARES, S. S. Trindade e Criação. Petrópolis: Vozes, 2007 e TAVARES, S. S. Teologia da Criação. Outro olhar - novas relações. Petrópolis: Vozes, 2010.

${ }^{9}$ A este propósito, consultem-se: REIMER, H. Toda a Criação. Bíblia e Ecologia. São Leopoldo: Oikos Editora, 2006; MESTERS, C.; OROFINO, F. "Novos céus e nova terra, vida no campo e na cidade. A sustentabilidade da vida e a espiritualidade". In: SOTER (Org.). $21^{\circ}$ Congresso Anual da Sociedade de Teologia e Ciências da Religião. São Paulo: SOTER/ Paulinas, 2008, edição digital ebook, pp. 11-21. Disponível em: <http://ciberteologia.paulinas. org.br/portals/44/LivroDigital.pdf>. Acesso em 13 de março de 2009.

${ }^{10}$ Consultem-se os seguintes trabalhos que se inserem nessa busca de uma teologia da Criação em diálogo com as ciências: BERRY, Th. The Drean of the Earth. San Francisco: Sierra Club Books, 1988 [trad. Brasileira: Petrópolis: Vozes, 1991]; MOLTMANN, J. Deus na criação Doutrina ecológica da criação. Petrópolis: Vozes, 1992; LAMBERT, D. Sciences et théologie. Les figures d'un dialogue. Bruxelles: Lessius, 1999; SUSIN, L.C. (Org.). Mysterium Creationis um olhar interdisciplinar sobre o universo. São Paulo: Paulinas, 1999; EUVÉ, F. Penser la Création comme jeu. Paris: Les Éditions du Cerf, 2000 [trad. brasileira, São Paulo: Paulinas, 2006]; JUNGES, J. R. Ecologia e Criação. São Paulo: Edições Loyola, 2001; SUSIN, L. C. A criação de Deus. Teologia Sistemática 5: Deus e criação. Valencia/São Paulo: Siquem/Paulinas, 2003; KÜNG, H. O princípio de todas as coisas. Ciências naturais e religião. Petrópolis: Vozes, 2007; MOLTMANN, J. Ciência e sabedoria. Um diálogo entre ciência natural e teologia. São Paulo: Loyola, 2007.
} 
íntima relação com o presente e com o futuro. Agora, a origem passou a ser entendida como fundamento. Fundamento esse que fornecia as melhores garantias para que o projeto do ser humano moderno, concebido como sujeito pensante, pudesse ser levado a termo de forma voluptuosa e desimpedida. Foi nesse contexto que se aplicou ao Criador a imagem do "relojoeiro".

Outras imagens do Criador muito difundidas no horizonte da cultura moderna se colocam nessa mesma linha: a imagem do Criador como "o grande Arquiteto" ou outra mais recente, difundida pelos adeptos do "Intelligent Design", que o apresentam como o "Intelligent Designer". A primeira conseqüência dessas imagens é a de instrumentalizar o Criador, concebendo-o como o fundamento e a certeza do projeto ideado e realizado pelo sujeito moderno.

Fomos, na verdade, demasiadamente habituados a conceber Deus como o fundamento estático de todas as coisas, circunscrevendo-o quase exclusivamente ao passado. Conseqüentemente, o passado passou a ser considerado como determinante do presente e do futuro. Nós modernos, particularmente, construímos grandes sistemas nos quais não apenas o presente resultava condicionado inelutavelmente pelo passado, mas também o futuro, que passou a ser concebido como algo programado e, portanto, absolutamente previsto. Deste modo, o futuro acabou destituído de toda e qualquer ulterioridade.

Outra dificuldade provocada por essas imagens é a de relegar o Criador a regiões periféricas da realidade, condenando-o a uma situação de indiferença e de alienação face ao mundo. São imagens que, no fundo, traem uma concepção do Criador como um intervencionista. Por se encontrar fora da realidade, em determinados momentos críticos, ele intervirá como alguém que se intromete e intervém na trama da vida da qual ele não participa ordinariamente. Um deus assim se coloca em uma situação de oposição diametral ao Deus encarnado que nos foi revelado por Jesus Cristo e que constitui, portanto, a raiz de nossa fé.

O grande limite dessas imagens modernas do Criador e da criação é concebê-los como realidades que se dão no assim chamado reino da necessidade. Elas resultam necessárias com o intento de fundamentar e sustentar o inteiro projeto do ser humano moderno. Tudo parece circunscrito a um script predeterminado ou preestabelecido. Por alguma razão, as coisas tinham que existir e tinham que existir do jeito que são. Nesse sentido, elas comprometem a concepção bíblica da Criação como um evento inusitado, expressão da pura gratuidade de um Criador generoso 


\subsection{Narrativas bíblicas da Criação}

A Bíblia testemunha uma variedade de narrativas da Criação. Essa pluralidade por si só nos remete à importância da fé na Criação no universo religioso judeu-cristão. Quanto mais intensa, de fato, uma experiência, tanto mais ela fomenta uma variedade incontida de expressões. Embora sejam visíveis as semelhanças com os mitos das origens dos povos vizinhos, saltam aos olhos peculiaridades dos relatos bíblicos da criação. Em contato com outras tradições, o povo eleito admira, seleciona e absorve elementos de seus mitos das origens. Tais elementos, contudo, são recompostos e ressignificados no horizonte de narrativas bem tecidas em torno às dimensões peculiares e, portanto, constitutivas da fé bíblica.

Os mitos das origens constituem grosso modo cosmogonias $\mathrm{e}$ representações do caos primitivo caracterizado pela indistinção. Os relatos bíblicos deixam transparecer, de algum modo, essa passagem do caos primordial para uma situação de harmonia propiciadora da vida. Todavia, tais relatos introduzem elementos que justificariam um processo de "demitologização" colocado em prática pelos autores bíblicos. As narrativas bíblicas, todas elas, falam de criação ${ }^{11}$. Interpretar a origem do mundo como Criação, significa concebê-la como dom oferecido no bojo de uma relação singular entre Criador e criaturas. Na origem dessas narrativas, se encontra a fé em um Deus pessoal que livremente deseja criar criaturas que possam participar de sua própria vida. Nesse sentido, compreende-se o diferencial de tais relatos: a narração da criação como uma experiência relacional.

Esse processo de "demitologização" vem acompanhado por seu correlato: o processo de "desmistificação". Os mitos das origens, em geral, elaborados e difundidos a partir dos ambientes de Coorte, serviam a uma verdadeira mistificação de relações de poder e de sopruso sofridas pelas maiorias pobres e indefesas. Não raramente, tais mitos se revelavam como instrumento de encobrimento das injustiças e dos desmandos por parte dos poderosos e dominadores. Em tais casos, os mitos das origens eram expressão de um expediente generalizado: a instrumentalização da religião como legitimadora do poder constituído: poder econômico, político, social e cultural.

O povo bíblico é particularmente sensível à vida experimentada como evento. Daí sua preocupação com a história e o caráter inusitado de seus

${ }^{11}$ Cf. HEIMER, H. "Criação, natureza e meio ambiente". Caminhos 8 (2010/2), pp. 53-68. 
acontecimentos e processos. Os processos cósmicos não lhe passavam despercebidos, apenas que eram acolhidos e experimentados na sua íntima relação com a historicidade da vida. Nesse sentido, percebe-se nas narrativas bíblicas da criação uma estreita relação entre as experiências de libertação/ salvação e criação. No transfundo de tais narrativas, encontra-se uma profissão de fé profundamente coerente: o mesmo Deus que se revela no presente como "presença libertadora" e que acompanha a caminhada de seu povo na direção de um futuro bom e reconciliador, é aquele que se revela na origem como criador de tudo quanto existe.

A fé no Deus criador ressurgiu justamente nos momentos mais críticos da história do povo bíblico. Momentos em que sua fé nas promessas divinas e sua esperança no futuro encontravam-se ameaçadas pela dureza e crueldade do presente. E a fé no Deus criador lhe servia de estímulo a recuperar a confiança na presença e interpelação desse mesmo Deus no seu presente, abrindo perspectivas na direção do futuro. É nesse preciso contexto que ecoam as palavras do Dêutero-Isaías: "Não vos lembreis das coisas passadas, nem considereis as antigas. Eis que faço uma coisa nova! Já está despontando: porventura não o percebeis?" (Is 43,18-19a). Portanto, a fé bíblica no Deus Criador comporta uma tríplice dimensão de Criação: 1) a criação no princípio: "No princípio criou Deus o céu e a terra" (Gn 1,1);2) a criação como evento que se revela no curso da história (cf. o texto do profeta Isaías, citado acima); 3) a criação como plenitude da obra divina: "Eis que faço novas todas as coisas" (Ap 21,5).

Não há, portanto, na tradição de fé do povo bíblico, nenhum ranço de separação, menos ainda de contraposição, entre os eventos da criação, da história da salvação e dos tempos derradeiros e definitivos. Eles distinguem a história da origem primordial do tempo e da plenitude de todo o tempo. Todavia não as separam nem as contrapõem. Na sua distinção, o tempo escandido na sua tríplice dimensão se encontra habitado pela presença do Deus bíblico que se revela como presença libertadora.

Essa específica experiência de fé testemunhada pelo povo bíblico provocou esse duplo processo de "demitologização/desmistificação" que se verificou na passagem dos mitos às metáforas no interior dos relatos bíblicos da criação. Consideraremos aqui, ainda que brevemente, a título de exemplo, três relatos bíblicos da Criação: Gn 2,4b-25; Gn 1,1 - 2,4a e $\operatorname{Pr} 8,22-31$. 
Na narrativa de Gn 2,4b-25, afloram relações de pertença e de cuidado como constitutivas do ato criador de Deus. E tudo é dito metaforicamente. O relato inicia falando de uma dupla carência, responsável pelo caráter inóspito e desértico da terra: a falta de alguém que cuide/cultive a terra e a carência de chuvas que a tornem fértil. O ser humano "cultivador/cuidador" (Adam) é modelado pelo Criador a partir da própria "terra cultivável” (adamah). É, de fato, essa experiência de íntima pertença que faz do ser humano o cuidador/ cultivador da terra. Nesta narrativa, o Criador aparece como aquele artesão cuidadoso que plasma o ser humano do próprio barro da terra para que ele seja seu cultivador/cuidador. Porque feito do barro da terra, o ser humano é chamado a ser o cultivador da terra. Pertença e cuidado, portanto, constituem simultaneamente a marca indelével do ser humano criado por Deus.

\section{b. A vida como diálogo: interpelação e resposta (Gn 1,1-2,4a)}

No relato de Gn 1,1 - 2,4a, o Criador cria mediante a eficácia de sua palavra. O surgimento da vida é metaforicamente apresentado como fruto da interpelação divina. Deus mesmo chama à vida suas criaturas, comunicandolhes uma singular incumbência. A própria existência das criaturas é concebida como uma vocação. As criaturas todas são criadas no bojo de um diálogo existencial e salvífico. Deus as chama, cada uma por nome, e no próprio nome reside a incumbência primordial de cada criatura. Esta eficácia da Palavra divina que cria a totalidade da realidade será responsável também pela criação da história enquanto trama amorosa da relação pessoal do Deus bíblico com seu povo escolhido. Toda a ação criadora de Deus é destinada ao shabat, culminância da criação. Na celebração da criação se encontra seu sentido. Assim como tudo quanto existe brotou gratuitamente do desejo generoso do Criador, o louvor e a ação de graças constituem a melhor correspondência das criaturas à generosidade e amor de seu Criador.

Portanto, é o Criador quem cria seja pela habilidade e genialidade de suas mãos seja pela força e eficácia de sua Palavra. Em ambos os casos, o cuidado do Criador é explicitado como fonte e origem de tudo quanto existe. Em ambos os relatos, no transfundo de suas metáforas, transparece a presença simultânea de dois elementos constitutivos da fé bíblica: 1) a origem divina do mundo: 2) a autonomia do mundo e a liberdade de suas criaturas face ao 
Criador. Essa consciência se encontra na raiz da atitude tipicamente bíblica face à profissão de fé no Deus criador: a experiência da gratuidade da vida.

c. A vida como jogo: a experiência de gratuidade (Pr 8,22-31)

A concepção da criação como gratuidade transparece de maneira mais clara ainda nos relatos sapienciais da Criação, dentre os quais destaca-se o texto de $\operatorname{Pr} 8,22-31$ :

O Senhor criou-me como início de sua ação, antes de suas obras mais remotas. Desde tempos imemoriais fui constituída, desde as origens, desde os primórdios da terra. Nasci quando não existiam os oceanos, quando não havia fontes de águas abundantes. Antes que fossem fixados os montes, antes das colinas fui dada à luz. Ele ainda não tinha feito a terra e os campos, nem os primeiros elementos do mundo. Quando colocava os céus, ali estava eu. Quanto traçava o horizonte sobre o Oceano, quando condensava as nuvens lá no alto e continha as fontes do Oceano, quando fixava ao mar seus limites - prescrições que as águas jamais ultrapassam - e lançava os fundamentos da terra, eu estava ao seu lado como criança ${ }^{12}$; entusiasmando-me, dia após dia, brincando todo o tempo em sua presença, divertindo-me em seu orbe.

Nesse texto, a obra da criação é explicitamente associada à experiência do jogo. Trata-se de uma linguagem metafórica que salienta a dimensão lúdica da criação que se coaduna bem com a concepção da criação como experiência de gratuidade. A obra criadora de Deus é narrada numa proximidade muito grande com a narrativa da criação de Gn 1,1 - 2,4a. Trata-se do gesto de delimitação e de distinção para que o caos se transforme em um espaço harmonioso e propício à vida. $\mathrm{O}$ diferencial desse relato em relação aos demais é a figura da sabedoria, metaforicamente, descrita como uma criança que, durante todo o tempo, brinca na presença do Criador, divertindo-se e entusiasmando-se dia após dia com o conjunto de suas criaturas.

Essa figura da sabedoria que como uma criança se diverte, brinca, e se entusiasma na presença do Deus criador oferece as condições para pensarmos a criação como uma experiência lúdica. E essa metáfora da Criação como um

\footnotetext{
${ }^{12}$ Seguimos, aqui, a F. Euvé que, baseando-se em estudos da exegese bíblica crítica, traduz o termo âmôn por criança: cf. EUVÉ, F. Pensar a Criação como jogo. São Paulo: Paulinas, 2006, pp. 132-142.
} 
jogo talvez seja a mais adequada para reassumir toda a riqueza de detalhes da fé bíblica na criação como experiência de gratuidade porque, no fundo, fruto do desejo livre e gratuito de um Deus que é, ao mesmo tempo, criador e Pai.

\subsection{Perspectivas: outro olhar - novas relações}

Sob um novo olhar, Deus se revela como a fonte de onde promanam todas as possibilidades e, ao mesmo tempo, como a origem de todo o tempo a partir da dinamicidade própria do futuro. Ao invés, portanto, de insistirmos em interpretar o Deus bíblico como a determinação de todo o real, talvez fosse o caso de concebê-lo como a "possibilização máxima do possível". Um Deus paciente que respeita e acompanha o ritmo natural do inteiro cosmos e de cada criatura, o ritmo da humanidade e de cada pessoa humana. Sua paciência não é sintoma de indiferença ou de passividade. Ele é o primeiro a se engajar no processo lento, porém eficaz de transformação e, portanto, de plenificação de cada criatura e da inteira criação. E essa sua atitude é expressão de sua peculiar condescendência proveniente de sua solidariedade e gratuidade singulares.

Significativa nesse contexto a afirmação de Bonhoeffer: "Deus é impotente e fraco no mundo, e exatamente assim, Ele está conosco e nos ajuda". Como também a do filósofo Gianni Vattimo: "Só um Deus fraco pode nos salvar agora". Assim sendo, uma autêntica teologia da criação só poderá ser tecida a partir da experiência de kénosis que constitui a experiência-fonte, originante e fomentadora, das interrelações intratrinitárias e das distintas relações que o Deus Trindade instaura para conosco ao longo da história da salvação e por entre os meandros sutis de nossa trama cósmica. A criação se nos afigura, em última instância, como uma autêntica experiência de kénosis (esvaziamento, despojamento) que se revela mediante um tríplice movimento: retração do Pai que, ao nos chamar à existência, cria-nos "do nada"; despojamento do Filho que nos salva, resgatando-nos, mediante seu gesto de extrema solidariedade, "do nada do pecado"; e, por último, escondimento do Espírito Santo que continua realizando com lento vagar sua obra de santificação mediante a plenificação das pessoas, da história e do cosmos inteiro a partir "do nada do mundo".

Conceber a Criação à luz do Mistério da Trindade significa ademais resgatar o sentido da relação singular entre Criador e criaturas. O termo Criação remete à experiência do dom e da gratuidade divinas. Dizer criação pressupõe a consciência da relação primordial entre Criador e criatura. Neste sentido, criação difere substancialmente de termos como, por exemplo, natureza ou 
cosmos. Ao nos reconhecermos criaturas, exprimimos a consciência de que a vida se nos afigura como oferecida gratuitamente. Poderíamos existir de outro modo ou sequer existir. E, no entanto, existimos. Portanto, o nosso existir revela um querer, uma intencionalidade, primários. Fomos queridos por alguém, por um Criador, e, portanto, passamos a existir. Não são, a rigor, necessidades intrínsecas que justificam nossa existência como tal. $\mathrm{O}$ que de fato testemunhamos é que somos queridos por alguém que deseja que existamos. E este alguém nos quer assim como somos. Também aquelas circunstâncias que caracterizam nossa existência são queridas como tais pelo Criador e correspondem, em última instância, a uma intencionalidade e querer gratuitos dele.

Não existem, portanto, explicações que dêem conta do porquê de nossa existência. E aqui, precisamente, nosso Criador se revela como Absoluto, manifestando assim sua radical diferença face ao caráter intrinsecamente contingente de suas criaturas. O Criador não está vinculado a nada. Não existe nada fora de Deus que o possa condicionar. Ele é o Ab-solutus por excelência. E seu querer e agir são absolutamente gratuitos. O fio condutor, portanto, que atravessa a inteira realidade criada é constituído pela experiência da gratuidade em todas as suas expressões. Não existem, a rigor, leis ou relações necessárias que caracterizam a relação entre o Criador e suas criaturas. E, por esta razão, estão descartadas todas as tentativas de encontrar explicações lógicas e necessárias que dêem razões à existência nossa e das demais criaturas.

Permeia a complexidade de tudo quando existe a gratuidade amorosa do Criador que se revela mediante um querer gracioso, caracterizado pelo cuidado e pelo enternecimento para com cada criatura e para com a inteira realidade criada. Este querer divino instaura de maneira consistente as legítimas buscas de sentido. A preocupação maior e mais fundamental do ser humano passa a ser então auscultar as interpelações do Criador inscritas em sua mais recôndita interioridade, no seio das relações interpessoais, nos meandros sutis da história e nas fibras mais íntimas da inteira realidade criada.

Porque expressão do querer mais íntimo de um Pai que deseja criaturas para poder instaurar com elas relações de comunhão, a criação se revela como o palco da trama amorosa e, por isso mesmo, dramática do amor esponsal entre Deus e suas criaturas. Somos, enquanto criaturas, radicalmente diferentes do criador. Somos diferentes não para selar nossa irremissível separação; mas, ao contrário, para nos decidirmos livre e conscientemente pela relação, fomentando assim o encontro e tecendo teias de comunhão. 


\section{Considerações finais: a transparência divina na trama da vida}

À conclusão de nosso estudo cujo objetivo é salientar a necessidade de uma nova teologia da criação em resposta aos urgentes desafios postos pela Tecnociência e pelo Mercado, gostaríamos de tecer algumas considerações. Intenção nossa não é propriamente concluir dando um fecho às questões surgidas no decorrer da argumentação. Ao contrário, as considerações aqui oferecidas querem suscitar novos questionamentos com o objetivo de abrir o leque das discussões acerca dessa importante temática.

Conceber a complexidade dos seres existentes no mundo como criação significa por si só compreendê-los no bojo de uma relação prévia e concomitante. Pois só se pode falar em criação sob o pressuposto de uma relação primordial entre Criador e criaturas. Enquanto criaturas poderíamos não existir. Não há nada que justifique a necessidade de nossa existência. No entanto, existimos. Porque assim o quer o Criador. Somos expressão do desejo livre, generoso e gratuito de Alguém que quer que existamos. O sentido que permeia a complexidade da criação, portanto, é a gratuidade. Vimos como as narrativas bíblicas insistem nessa dimensão de gratuidade presente em toda a criação. No seio da Trindade santíssima, referencial para a nova teologia da criação, impossível compreender as relações entre os divinos três senão a partir da gratuidade que os congrega na comunhão e no amor.

Os relatos bíblicos testemunham a intenção do criador de criar criaturas que pudessem tecer entre si relações de harmonia. Uma harmonia em que cada criatura, por ser singular, constitui uma peculiar linguagem no concerto da inteira criação. Como, então, a partir dessa boa-nova da gratuidade desconstruir essa cultura da funcionalidade e da mercantilização que tem fortemente caracterizado as relações no mundo em que vivemos?

Pressuposta ser a gratuidade fio condutor da inteira trama da criação, pano de fundo do cenário histórico e senda matricial do itinerário existencial de cada pessoa, perguntamo-nos: como seguir alimentando mentalidades e atitudes que encarnam uma violência cabal a nós e às demais criaturas? Como desconstruir os processos de desumanização e desnaturalização, ambos produzidos pela "tecnificação" e "mercantilização" da vida? Tendo por base essa boa-nova da criação como seguir submetendo-nos a um saber que se esgota na instrumentalidade e que, portanto, manifesta uma peculiar indigência na sua incapacidade de nos remeter às questões do sentido e de nos conduzir pelos meandros sutis das sendas da transcendência? 
Em meio a tudo isso, somos interpelados a testemunhar o fenômeno da transparência divina no tecido íntimo da trama da vida. Ao professar a fé no Deus trino e uno, as comunidades cristãs propiciam uma peculiar relação entre Transcendente e imanente. A profissão de fé no Deus Pai criador salienta o caráter absolutamente transcendente do Deus trino e uno. Ele é o criador absoluto, que cria sem pressupostos e sem condições, e, portanto, o Senhor de tudo quando existe, selando assim sua irredutível transcendência face ao caráter contingencial de suas criaturas. A profissão de fé no Filho unigênito de Deus que se encarnou, sublinha a singela solidariedade de Deus para com suas criaturas. É o evento da mais radical irrupção do Todo no fragmento, da emergência do transcendente a partir do âmago mesmo da imanência. A profissão de fé no Espírito Santo, como evento da interiorização do próprio Deus no coração mesmo da matéria, da história, da corporeidade de suas criaturas, acena para a revelação do Deus trino e uno como a interioridade mais íntima do cosmos, da história e da vida de cada uma e de todas as criaturas.

É imprescindível, portanto, dialetizar transcendência e imanência através da consideração do evento da interiorização do próprio Deus no coração mesmo da matéria, da história e dos corpos de suas criaturas. O evento da interioridade de Deus, mediante Seu Espírito, no coração mesmo de suas criaturas, impede toda e qualquer bipolaridade rígida e excludente entre transcendência e imanência. A profissão de fé no Deus trino e uno propicia aos cristãos, portanto, uma peculiar relação entre transcendente e imanente: nem pura transcendência, nem mera imanência, mas a celebração da transparência divina na trama da Criação.

\section{Referências bibliográficas}

ASSMANN, H.; HINKELAMMERT, F. A idolatria do Mercado. Ensaio sobre economia e teologia. São Paulo: Paulinas, 1989.

BAUMAN, Z. Vida para consumo. A transformação das pessoas em mercadoria. Rio de Janeiro: Zahar, 2008.

BERRY, Th. The Drean of the Earth. San Francisco: Sierra Club Books, 1988 [trad. Brasileira: Petrópolis: Vozes, 1991].

EUVÉ, F. Penser la Création comme jeu. Paris: Les Éditions du Cerf, 2000 [trad. brasileira, São Paulo: Paulinas, 2006]. 
FELINTO, E. A Religião das Máquinas. Ensaios sobre o imaginário da Cibercultura. Porto Alegre: Sulina, 2005.

FELINTO, E. "O Ciberespaço como cidade ideal - a internet e a fantasia da Jerusalém digital”. In: TAVARES, S. S.; BRUNELLI, D. Evangelização em Diálogo. Novos cenários a partir do paradigma ecológico. Petrópolis: Instituto Teológico Franciscano/Vozes, 2014, pp. 70-90.

GALIMBERTI, U. Psiche e techne. O homem na idade da técnica. São Paulo: Paulus, 2006.

GORZ, A. "A crise e o êxodo da sociedade salarial". Cadernos IHU Idéias 31. São Leopoldo: Ed. Unisinos, 2005.

GORZ, A. O imaterial. São Paulo: Annablume, 2005.

HEIMER, H. "Criação, natureza e meio ambiente". Caminhos 8 (2010/2), pp. 53-68.

JUNGES, J. R. Ecologia e Criação. São Paulo: Edições Loyola, 2001.

KÜNG, H. O princípio de todas as coisas. Ciências naturais e religião. Petrópolis: Vozes, 2007.

LAMBERT, D. Sciences et théologie. Les figures d'un dialogue. Bruxelles: Lessius, 1999.

LIBANIO, J. B. A religião no início do milênio. São Paulo: Loyola, 2002.

LIPOVETSKY, G. O império do efêmero. A moda e seu destino nas sociedades modernas. São Paulo: Companhia das Letras, 2006.

MARCHESINI, R. "Uma hermenêutica para a tecnociência". In: NEUTZLING, I.; ANDRADE, P. F. C. de (Orgs.). Uma sociedade póshumana. Possibilidades e limites das nanotecnologias. São Leopoldo: Editora Unisinos, 2009, pp. 153-182.

MESTERS, C.; OROFINO, F. "Novos céus e nova terra, vida no campo e na cidade. A sustentabilidade da vida e a espiritualidade". In: SOTER (Org.). $21^{\circ}$ Congresso Anual da Sociedade de Teologia e Ciências da Religião. São Paulo: SOTER/Paulinas, 2008, edição digital ebook, pp. 1121. Disponível em: <http://ciberteologia.paulinas.org.br/portals/44/ LivroDigital.pdf $>$. Acesso em 13 de março de 2009.

MOLTMANN, J. Deus na criação - Doutrina ecológica da criação. Petrópolis: Vozes, 1992. 
MOLTMANN, J. Ciência e sabedoria. Um diálogo entre ciência natural e teologia. São Paulo: Loyola, 2007.

MOREIRA, A. (Org.). O capitalismo como religião. Goiânia: Ed. da PUC Goiás, 2012.

MOREIRA, A.; LEMOS, C. T., QUADROS, E. G. (Orgs.). A religião da mídia e a mídia da religião. Goiânia: Ed. da PUC Goiás - Gráfica e Editora América, 2012.

MO SUNG, J. Idolatria do capital e a morte dos pobres. São Paulo: Paulinas, 1989.

POLANYI, K. A grande transformação. As origens da nossa época. Rio de Janeiro: Campos, 2000.

REIMER, H. Toda a Criação. Bíblia e Ecologia. São Leopoldo: Oikos Editora, 2006.

SUSIN, L. C. (Org.). Mysterium Creationis um olhar interdisciplinar sobre o universo. São Paulo: Paulinas, 1999.

SUSIN, L. C. A criação de Deus. Teologia Sistemática 5: Deus e criação. Valencia/São Paulo: Siquem/Paulinas, 2003.

TAVARES, S. S. Trindade e Criação. Petrópolis: Vozes, 2007.

TAVARES, S. S. Teologia da Criação. Outro olhar-novas relações. Petrópolis: Vozes, 2010.

\section{Sinivaldo Silva Tavares}

Doutor em Teologia Sistemática pela Pontificia Università Antonianum Professor e pesquisador na Faculdade Jesuíta de Filosofia e Teologia (FAJE) Professor e pesquisador no Instituto São Tomás de Aquino (ISTA) Belo Horizonte / MG - Brasil E-mail: freisinivaldo@gmail.com

Recebido em: 12/06/15

Aprovado em: 11/11/15 